The Sustainable City XII 583

\title{
MEMBRANE SELECTION FOR ORGANIC CONTAMINANTS REMOVAL FROM HARTBEESPOORT DAM WATER IN SOUTH AFRICA
}

\author{
AMOS ADENIYI, RICHARD MBAYA, MAURICE ONYANGO, PATRICIA POPOOLA \& THABO BROOMS \\ Department of Chemical, Metallurgical and Materials Engineering, Tshwane University of Technology, \\ Private Bag X680, Pretoria 0001, South Africa
}

\begin{abstract}
Membrane filtration of raw water obtained from Hartbeespoort dam in South Africa and spiked with four different organochlorides pesticides and three polyaromatic hydrocarbons was done using three different commercially available membranes (AFC 40, AFC80 and AFC99). The purpose was to determine important membrane characteristics for removal of organic contaminants and enhance water recovery. AFC40, a nanofiltration membrane, showed a modular structure, has $2.9 \%$ porosity and average roughness 0.76 . AFC 80 , a reverse osmosis membrane, showed little modular structure, has $2.9 \%$ porosity and average roughness 0.79 . AFC 99 , another reverse osmosis membrane was tight and showed no nodular structure, percentage porosity was 0.2 while average roughness was 0.67 . All the membranes are hydrophilic and gave more than $99 \%$ rejection of organic solutes however water recovery was higher with AFC40 which is more hydrophilic (Contact angle $30^{\circ}-40^{\circ}$ ) and lowest with AFC99 which is less hydrophilic (Contact angle $40^{\circ}-63^{\circ}$ ). EDX results showed that AFC99 has the lowest sodium and sulphur contents. This may have contributed to the absence of modular structure, lower hydrophilicity, and its tightness. The FTIR analysis of the membranes indicated a significant presence of amides group (peak at $1650 \mathrm{~cm}^{-1}$ ) and acyl and phenyl C-O groups in all the membranes (peak at $1150 \mathrm{~cm}^{-1}$ ). The presence of ortho disubstituted aromatic group (peak at $74 \mathrm{~cm}^{-1}$ ) was observed in both AFC40 and AFC 80 but not in AFC99. This is suspected to have contributed to the tight structure of AFC99. AFC40 had little effect on the conductivity of the feed water. Membranes with higher nodular structure have a higher porosity. The presence of nodular structure increases water recovery but also allows the passage of some dissolved solids, and is therefore important in the selection of membranes for organic contaminants removal from hartbeespoort dam water.
\end{abstract}

Keywords: Hartbeespoort dam, organic solutes, membranes, reverse osmosis, nanofiltration.

\section{INTRODUCTION}

Chemical pollution of natural waters has already become a major public concern in almost all parts of the world since it has largely unknown long-term effects on aquatic life and on human health [1]. Most of these chemical pollutants can be removed by the conventional treatment method of coagulation and sedimentation. However, the occurrence of micropollutants in both surface and underground water is a major concern to water practitioners all over the world [2], [3]. There are two major reasons for this, the first one is the fact that the adverse effect of these micro-pollutants is significant and the extent of damage to human is not well documented if taken through drinking water [4]. The other reason is that the conventional treatment methods may not be adequate for the removal of these micropollutants [2], [5]. The technology options available for the removal of these micro-pollutants are advanced treatment methods such as Advance Oxidation Processes (AOP), Granular Activated Carbon (GAC) or Membrane Technology [5]. The addition of more advanced final treatment steps (usually involving oxidation by $\mathrm{H}^{2} \mathrm{O}^{2}$ or $\mathrm{O}^{3}$, and granular activated carbon GAC-filtration) is generally considered to be effective, although significant problems still arise, mainly related to saturation of activated carbon, and to toxic chemical by-products, 
which may develop in the GAC filters under some conditions [3]. When a high water quality is desired, membrane processes such as reverse osmosis (RO) and nanofiltration (NF) might be used as tertiary treatment [6].

Hartbeespoort dam located in South Africa is a major source of drinking water. There is a water purification plant located near the dam which uses the conventional treatment method. However recent analysis of the dam water indicated the presence of micro-pollutants [7]. Membrane technology is being considered as an option in order to remove these micropollutants. The purpose of this work is to investigate three membranes for filtration of water obtained from Hartbeespoort dam in order to determine important membrane characteristics for removal of organic contaminants and enhance water recovery.

\section{MATERIAL AND METHOD}

\subsection{Material}

\subsubsection{Membrane}

Three membranes obtained from Xylem UK were used for the experiments. They are all made from 1,2-benzisothiazol-3(2H)-one, sodium salt. They are tubular membranes of about $32 \mathrm{~cm}$ in length and $1.4 \mathrm{~cm}$ in diameter. The trade names are AFC40, AFC80 and AFC99. AFC40 is a nanofiltration membrane while AFC99 and AFC80 are Reverse Osmosis membranes

\subsubsection{Source and characterization of dam water}

The raw water sample was obtained from Hartbeespoort dam located $25^{\circ} 45^{\prime \prime} 09.97^{\prime \prime} \mathrm{S}$, $27^{\circ} 53^{\prime} 04.39^{\prime \prime} \mathrm{E}$, about $37 \mathrm{~km}$ west of Pretoria and on the Crocodile River in North West Province, South Africa. Turbidity measurement was done using portable microprocessor turbidity meter HI93703) from HANNA. $\mathrm{pH}$ of process water was measured using Jenway $3510 \mathrm{pH}$ meter obtained from Lansec. The conductivity of water was determined with conductivity meter HI8033 obtained from HANNA while Total Dissolved Solid (TDS) was calculated from conductivity values with chemiasoft [8]. The raw water was pretreated using sand filtration and ultrafiltration.

\subsubsection{Preparation of organic solutes}

Amdany et al. [7], found PAHs at concentrations ranged from $30.0 \mathrm{ng} / \mathrm{L}$ to $51.5 \mathrm{ng} / \mathrm{L}$, and OCPs at 0.3 to $0.8 \mathrm{ng} / \mathrm{L}$ in the raw water obtained from the dam, organic solutes had to be prepared in order to increase the concentration of the solutes in the raw dam water. Four organochloride pesticides (OCPs) (4,4-DDT $10.4 \mu \mathrm{g} / \mathrm{L}$; Heptachlor $10.4 \mu \mathrm{g} / \mathrm{L}$; Aldrin 26.05 $\mu \mathrm{g} / \mathrm{L}$; Endosulfan sulfate $10.4 \mu \mathrm{g} / \mathrm{L}$ ); and three polyaromatic hydrocarbons (PAHs) (Pyrene $5.2 \mu \mathrm{g} / \mathrm{L}$; Naphthalene $4.15 \mu \mathrm{g} / \mathrm{L}$; Acenaphthene $10.4 \mu \mathrm{g} / \mathrm{L})$ solution were prepared. The preparation was done by dissolving a certain mass of the organics in either ethanol or methanol. This is because the organics were insoluble in water so each of them was dissolved in an organic solvent that is highly soluble in water. The organics were added to the raw water obtained from the dam after pretreatment.

\subsubsection{Process equipment}

A laboratory scale reverse osmosis pilot plant manufactured by Elettronica Veneta, Italy was used for the process experiment. 


\subsection{Method}

\subsubsection{Membrane characterization}

Fourier Transform Infrared Spectroscopy (FTIR)

Fourier transform infrared spectroscopy was performed on the membrane samples using a PerkinElmer Spectrum 100 spectrometer (PerkinElmer, USA) between $500 \mathrm{~cm}^{-1}$ and 4000 $\mathrm{cm}^{-1}$ wave number.

\section{Scan Electron Microscopy- Energy Dispersive X-Rays (SEM-EDX)}

The surfaces of the membranes were scanned using Joel Field Emission Electron Microscope JESM-7600F. The virgin membranes were mounted on a double-sided carbon tape and the surfaces were coated with iridium (about $5 \mathrm{~nm}$ thickness) in order to make it conductive before SEM analysis. The sample was exposed to the electron beam at an accelerating voltage of $15 \mathrm{KV}$. EDX data was obtained during SEM measurement. The SEM images were analyzed with the aid of WSxM 5.0 Develop 8 [9] and ImageJ [10], for surface roughness, percentage porosity, and pore identification.

\section{Contact angle}

Contact-angle measurements for the membrane were done using Sessile drop water measurement. The equipment used was Dataphysics Contact Angle Instrument (SCA 20, OCA 15EC). This was done by depositing sessile drops of deionized water on the dry surfaces of the membranes at room temperature. Images were captured five seconds after depositing the water drop onto the sample just before measurement of the contact angles. Three measurements were taken at different locations of the membrane sample. The average was calculated to obtain the membrane's contact angle.

\subsubsection{Membrane preparation}

The AFC 99 membrane was cleaned with a solution of $3 \mathrm{ml} / 1$ ( $70 \%$ Nitric Acid) at temperature $\left(55^{\circ} \mathrm{C}\right)$ and was recirculated for 30 minutes. As for AFC40 and AFC 80 membrane, they were cleaned with a solution of $2 \mathrm{ml} / 1\left(70 \%\right.$ Nitric Acid) at temperature $\left(55^{\circ} \mathrm{C}\right)$ and was also recirculated for 30 minutes.

\subsubsection{Process experiment}

The pretreated raw water was spiked with the organic solutes at the concentration (4,4-DDT $10.4 \mu \mathrm{g} / \mathrm{L}$; Heptachlor $10.4 \mu \mathrm{g} / \mathrm{L}$; Aldrin $26.05 \mu \mathrm{g} / \mathrm{L}$; Pyrene $5.2 \mu \mathrm{g} / \mathrm{L}$; Naphthalene 4.15 $\mu \mathrm{g} / \mathrm{L} ;$ Acenaphthene $10.4 \mu \mathrm{g} / \mathrm{L}$ ). The water was then treated in a cross-flow laboratory pilot plant at pressures of ranges from 5 to 45 bars. The flow rate was $1018 \mathrm{~L} / \mathrm{h}$. The flow diagram is shown in Fig 1. The permeate flow rate was taken against the applied pressures.

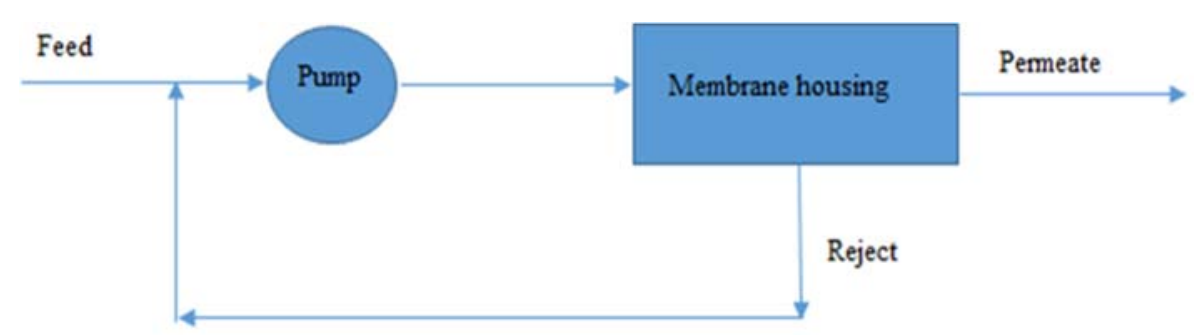

Figure 1: Flow diagram of the filtration process. 


\subsubsection{Organic contaminants rejection}

Two $500 \mathrm{ml}$ sample of permeate were taken for every filtration run conducted at $20 \mathrm{bars}$. The organic solutes present in the permeate were extracted using liquid-liquid extraction. The solvent used for the extraction was $100 \mathrm{ml}$ of dichloromethane $(99+\%$ purity). The extraction was done three times and the process done in duplicate. Excess water was removed from the extracted solvent using anhydrous sodium sulphate ( $99 \%$ purity). The sodium sulphate was activated in a furnace before use. This was done by heating the anhydrous sodium sulphate in the furnace at $600^{\circ} \mathrm{C}$ for 72 hours. The solvent was concentrated using a vacuum evaporator to about $2 \mathrm{ml}$. This was further concentrated to $0.5 \mu \mathrm{L}$ using Nitrogen gas. before being analyzed using Gas Chromatography Mass Spectrometry (GCMS). The clean extracts were analyzed for selected PAHs and OCPs by Shimadzu model 2010 plus gas chromatograph coupled with a model QP 2010 ultra, mass spectrometer (Shimadzu, Japan) using electron ionization and injected by a Shimadzu A0C-20i auto sampler. Equation 1 was used to calculate the rejection coefficient

$$
R=\left(1-\frac{c_{p}}{C_{f}}\right) \times 100 \%
$$

where $R$ is Rejection coefficient; $C_{p}$ is the solute concentration in permeate; $C_{f}$ is the solute concentration in the feed.

\section{RESULTS AND DISCUSSION}

\subsection{Membranes characteristics}

Fourier Transform Infrared (FTIR) Spectroscopy was used to analyze the chemical compositions of the three membranes by identifying the type of functional group in the active layer of the membrane. The FTIR results for each of the membrane reveal similar patterns as shown in Fig. 2. There is strong presence of saturated amides group and weak amines group in each of the membranes with equal intensity as indicated by peak at $1650 \mathrm{~cm}^{-1}$. The peak results from infrared radiation absorption by $\mathrm{C}-\mathrm{C}$ stretch aromatic and $\mathrm{N}-\mathrm{H}$ blends in the active polyamide layer. This is expected because the membranes are made from 1,2-benzisothiazol-3(2H)-one, sodium salt, a polyamide. There is a strong presence of acyl and phenyl C-O groups in all the membranes (peak at $1150 \mathrm{~cm}^{-1}$ ). There is also the presence of amines group with equal intensity for AFC99 and AFC40 but higher than the intensity of AFC80 (peak at $3310 \mathrm{~cm}^{-1}$ ). There is the presence of ortho disubstituted aromatic group in each of the membranes (peak at $740 \mathrm{~cm}^{-1}$ ) but was not observed in AFC99. This might have increased the tightness of AFC99 because Lee et al., [11], stated that the presence of substituted groups affects the membrane properties.

The qualitative EDX analysis of the membranes showed that AFC40 contain Carbon (75.31wt \%), Oxygen (14.66wt\%), Sodium (0.46 wt \%) and Sulphur (9.57 wt \%). AFC80 contains Carbon (61.19 wt \%), Oxygen (11.88 wt \%), Sodium (0.32 wt \%), Sulphur (25.14 wt \%). AFC99 contains Carbon (74.02 wt \%), Oxygen (19.04 wt \%), Sodium (0.26 wt\%), Sulphur $(6.06 \mathrm{wt} \%)$. It is of note that although the sodium contents of all the membranes are low, there is a progressive decrease in sodium contents from AFC40 (highest) to AFC99 (lowest). AFC99 has the lowest sodium and sulphur contents. This may have contributed to the absence of modular structure, lower hydrophilicity, and its tightness.

The contact angle is a measure of hydrophilicity of the membranes, the lower the values of contact angles, the more hydrophilic the membrane is. Materials that are hydrophilic 


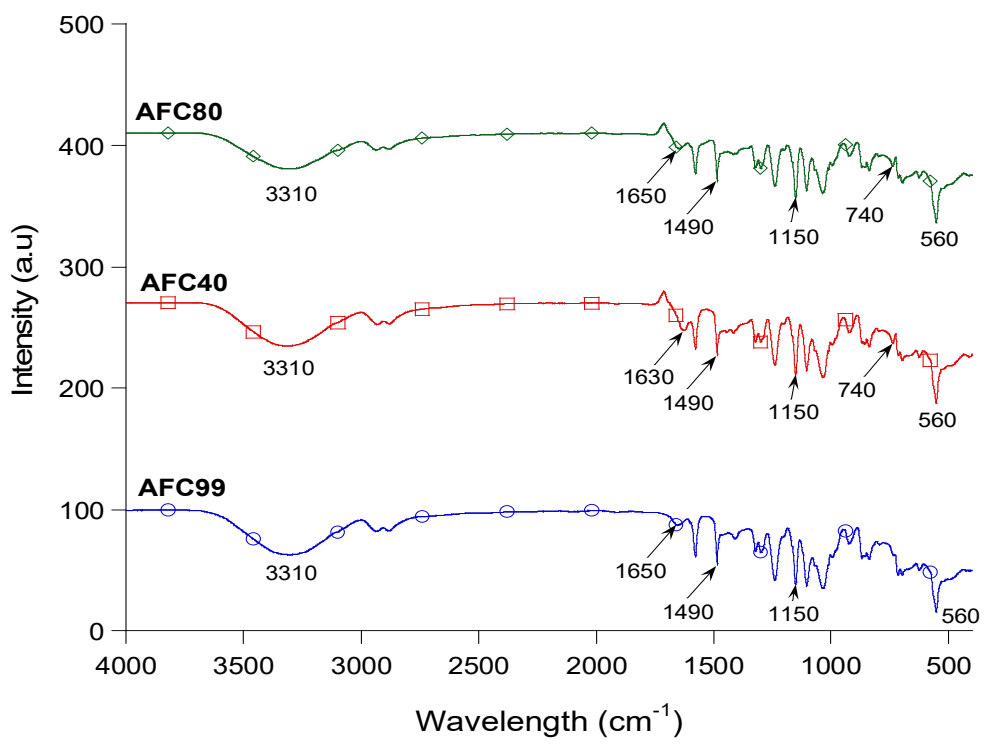

Figure 2: FTIR results for the membranes.

generally have contact angles less than $90^{\circ}$ while hydrophobic materials have contact angles greater than $90^{\circ}$. All the membranes investigated are hydrophilic, however, AFC40 exhibits more hydrophilicity $\left(30^{\circ}-40^{\circ}\right)$ than AFC $80\left(32^{\circ}-50^{\circ}\right)$ and AFC $99\left(40^{\circ}-63^{\circ}\right)$.

SEM images are as shown in Fig. 3. Both AFC40 and AFC 80 showed a nodular structure but nodules of AFC40 are bigger than that of AFC80. AFC99 showed no nodular structure. A progressive disappearance of the nodular structure is observed from AFC40 to AFC99. AFC40 a Nanofiltration membrane has the highest nodules while AFC99 a Reverse Osmosis membrane has none. However, although AFC 80 is a Reverse Osmosis membrane, it has some nodular structures but not as big and as pronounced as that of AFC40. This is likely to have an effect on the rejection of solute and water flux obtained from each of the membranes. Nodular structure increases the surface roughness of the membrane [12]. The nodular structure is more pronounced when the film is formed over polysulfone blend supports [13]. The nodular structure also depends on the reaction time during interfacial polymerization [14]. For shorter reaction time, the degree of cross-linking is lower, and the "thin and loose" polyamide skin layer will allow the higher permeation of both water and salt. As the reaction time extends, the thickness and cross-linking degree of the polyamide skin layer will increase, which results in reduced water flux and increased salt rejection. None of the images showed visible pores. All the images showed a dense finely dispersed structure with AFC99 showing higher density and fineness than AFC 80 and AFC40.

The SEM images were processed using ImageJ. The threshold images which separates the background from the objects are as shown in Fig. 4. The Figure showed that AFC40 is more porous than AFC80 and AFC99, while AFC99 showed a totally dense membrane. The porosity and roughness analysis of each of the membranes as determined using WSxM 5.0 Develop 8 software are shown in Table 1. AFC40 is more porous but less rough than AFC80. AFC99 has the lowest porosity and roughness, however, the porosity and roughness of each of the membranes are low. 


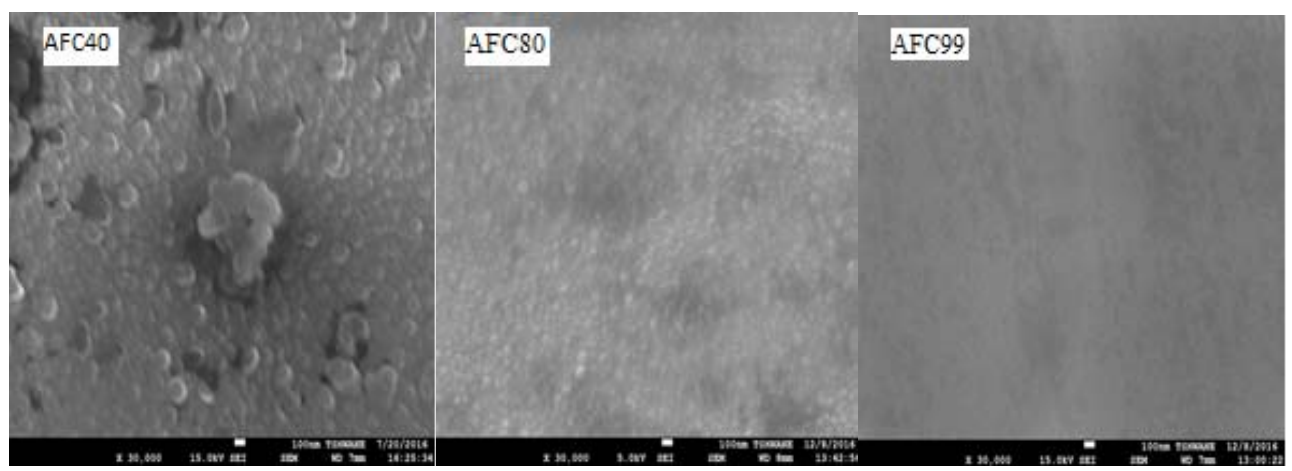

Figure 3: SEM images of the membranes at 30000x

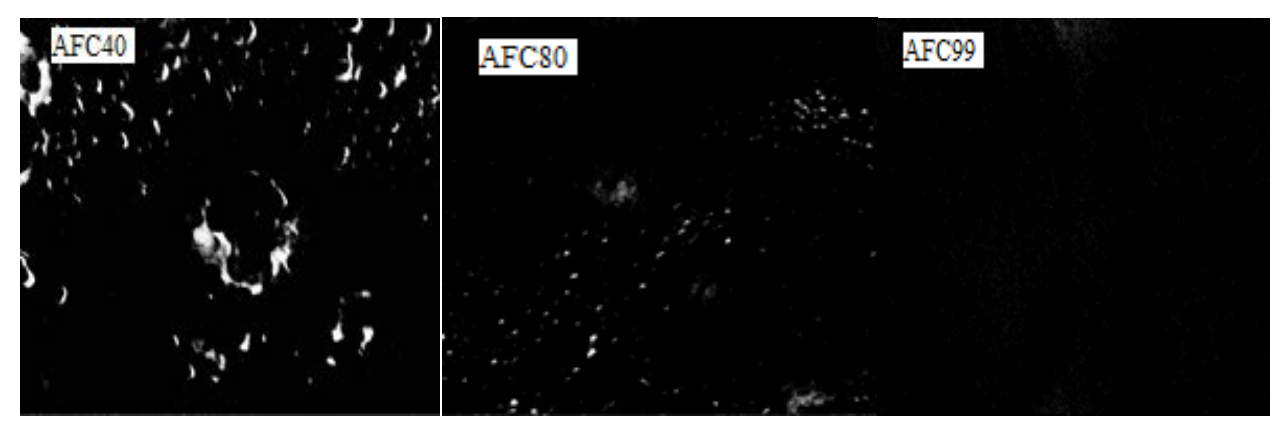

Figure 4: ImageJ threshold images of membranes.

Table 1: Comparison of porosity and roughness.

\begin{tabular}{|l|c|c|}
\cline { 2 - 3 } \multicolumn{1}{c|}{} & $\begin{array}{l}\text { Percentage } \\
\text { porosity }\end{array}$ & $\begin{array}{l}\text { Roughness } \\
\text { average }\end{array}$ \\
\hline AFC40 & $2.90 \%$ & 0.76 \\
\hline AFC80 & $0.90 \%$ & 0.79 \\
\hline AFC99 & $0.20 \%$ & 0.67 \\
\hline
\end{tabular}

\subsection{Process water}

The raw water used for the experiment was characterized for Conductivity, TDS, $\mathrm{pH}$ and Turbidity. The results are shown in Table 2 . The Conductivity of the raw water was low and hence the low value of the total dissolved solid (TDS). This means the water is of low ionic strength [15]. The sand filtration process increased the TDS and turbidity. The ultrafiltration process reduced the turbidity significantly as expected but has no effect on the Total Dissolved Solids. The final water fed into the membranes system is slightly alkaline, it is less turbid and also has low TDS. 
Table 2: Process water characterization [16].

\begin{tabular}{|l|l|l|l|}
\hline Parameter & Raw water & Sand filtration & Ultrafiltration \\
\hline $\begin{array}{l}\text { Conductivity } \\
(\mu \mathrm{S} / \mathrm{cm})\end{array}$ & 590 & 610 & 580 \\
\hline TDS $(\mathrm{mg} / \mathrm{L})$ & 306 & 317 & 301 \\
\hline pH & 8.23 & 7.97 & 8.22 \\
\hline Turbidity (NTU) & 4.16 & 4.95 & 1.13 \\
\hline
\end{tabular}

Table 3: Comparison of Conductivity, TDS, $\mathrm{pH}$ and Turbidity measurements.

\begin{tabular}{|l|c|c|c|c|}
\cline { 2 - 5 } \multicolumn{1}{c|}{} & $\begin{array}{l}\text { Conductivity } \\
(\mu \mathrm{S} / \mathrm{cm})\end{array}$ & $\begin{array}{l}\text { TDS } \\
(\mathrm{mg} / \mathrm{L})\end{array}$ & $\mathrm{pH}$ & $\begin{array}{l}\text { TURBIDITY } \\
(\mathrm{NTU})\end{array}$ \\
\hline Ultrafiltration permeate & 580 & 301 & 8.22 & 1.13 \\
\hline AFC40 permeate & 550 & 285 & 7.56 & 0.92 \\
\hline AFC80 permeate & 500 & 259 & 7.62 & 0.46 \\
\hline AFC 99 permeate & 260 & 133 & 7.42 & 0.38 \\
\hline
\end{tabular}

Table 3 shows the comparison of the effect of each membrane on the Conductivity, TDS, $\mathrm{pH}$, and Turbidity of the feed water. Both AFC 99 and AFC80 significantly reduced the turbidity of the process water. It is observed that only AFC99 has a significant effect on the TDS and this is due to the tightness of the membrane.

\subsection{Solute rejection}

The water obtained after the ultrafiltration stage was spiked with the organics before treatment on a reverse osmosis laboratory pilot plant. Results of rejection at a pressure of 20 bars are as shown in Tables 4 . Units are expressed in $\mathrm{ng} / \mathrm{L}$ for easy comparison. All the membranes exhibit greater than $99 \%$ rejection of the organic solutes. This may be due to low porosity of the membranes and high molecular weight of the organic solutes.

\subsection{Water recovery}

Water recovery increases with pressure as indicated by a progressive increase in permeate flow with pressure (Fig. 5). This is expected but at higher pressure, the rate of increase in permeate flow for each of membranes dropped. This is because the ionic strength of the

Table 4: Comparison of rejection.

\begin{tabular}{|l|l|l|l|l|l|l|l|}
\cline { 2 - 8 } & \multicolumn{7}{c|}{ Raw dam water spiked with PAH and OCP (ng/L) } \\
\cline { 2 - 8 } & $\begin{array}{l}\text { Heptachlor } \\
10,400\end{array}$ & $\begin{array}{l}\text { Aldrin } \\
26,050\end{array}$ & $\begin{array}{l}4,4- \\
\text { DDT } \\
10,400\end{array}$ & $\begin{array}{l}\text { Endosulfan } \\
\text { sulfate } \\
10,400\end{array}$ & $\begin{array}{l}\text { Pyrene } \\
5,200\end{array}$ & $\begin{array}{l}\text { Naphthalene } \\
4,150\end{array}$ & $\begin{array}{l}\text { Acenaphthene } \\
10,400\end{array}$ \\
\hline Membrane & \multicolumn{7}{|c|}{ Solute Concentration in Permeate (ng/L) } \\
\hline AFC40 & 0.06 & 2.44 & 0.09 & 0.7 & 0.49 & 0.13 & 0.72 \\
\hline AFC80 & 0.13 & 3.91 & 0.17 & 1.69 & 0.77 & 0.44 & 1.65 \\
\hline AFC99 & 0.05 & 1.05 & 0.07 & 0.54 & 0.28 & 0.16 & 0.62 \\
\hline
\end{tabular}




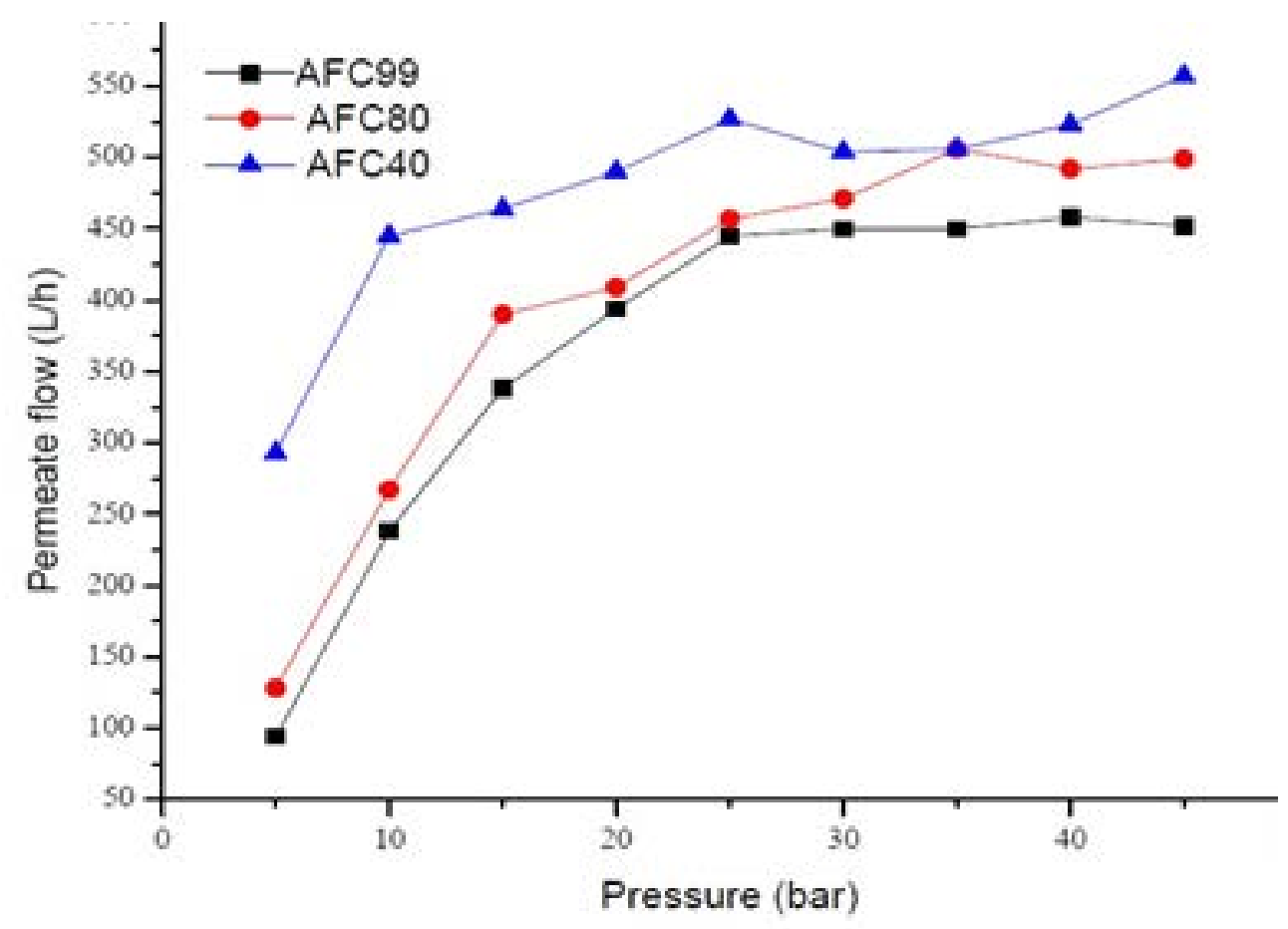

Figure 5: Comparison of permeate flow rates.

process water is low and consequently, the osmotic pressure is also low. This means high pressure is not needed for the filtration process. Fig. 5 actually showed that a pressure greater than 20bars is not needed. Generally, AFC40 showed higher water recovery than AFC80 and AFC99. This may be due to higher porosity which is attributed to the nodular structure of the membrane. The fact that the membrane has high hydrophilicity may also contribute to increase in permeate water flux.

\section{CONCLUSION}

All the membranes showed a significant presence of amides group because the membranes are made from polyamides. EDX results showed that AFC99 has the lowest sodium and sulphur contents. This may have contributed to the absence of modular structure, lower hydrophilicity, and its tightness. The presence of ortho disubstituted aromatic group (peak at $740 \mathrm{~cm}-1$ ) was observed in both AFC40 and AFC80 but not in AFC99. This is suspected to have contributed to the tight structure of AFC99. All the membranes are of low porosity and roughness. However, AFC40, a nanofiltration membrane, has a high nodular structure which causes an increase in porosity. AFC40 has higher porosity than AFC80 and AFC99 and gave highest permeate water flow. All the membranes gave adequate rejection of the organic solute although AFC40 has little effect on the conductivity of the process water. The nodular structure in AFC40 and its high hydrophilicity may have increased permeate flow, but the nodular structure allows the passage of some dissolved solids. The presence of nodular structure is important in the selection of membranes for organic contaminants removal from hartbeespoort dam water. 


\section{ACKNOWLEDGEMENTS}

The authors would like to acknowledge Tshwane University of Technology for funding, providing research facilities and laboratory equipment(s); Rand Water and National Research Foundation (NRF) for funding. A word of gratitude goes to Prof. Jonathan Okonkwo for giving us permission to use the organic chemistry laboratory facility

\section{REFERENCES}

[1] Loos, R., Gawlik, B.M., Locoro, G., Rimaviciute, E., Contini, S. \& Bidoglio. G., EUwide survey of polar organic persistent pollutants in European river waters. Environmental Pollution, 157, pp. 561-568, 2009.

[2] Bolong, N., Ismail, A.F., Salim, M.R. \& Matsuura, T., A review of the effects of emerging contaminants in wastewater and optional for their removal. Desalination, 239, pp. 229-246, 2009.

[3] Karabelas, A. \& Plakas, K., Membrane Treatment of Potable Water for Pesticides Removal, Herbicides, Theory and Applications. Prof. Marcelo Larramendy ed., ISBN: 978-953-307-975-2, InTech, Available from: http:/www.intechopen.com/ books/herbicides-theory-and-applications/membranetreatment-of-potable-water-forpesticides-removal, 2011.

[4] McKinlay, R., Plant, J.A., Bell, J.N.B. \& Voulvoulis, N., Endocrine disrupting pesticides: Implications for risk assessment. Environment International, 34(2), pp. 168-183, ISSN 0160-4120, 2008.

[5] Chang, H., Choo, K., Lee, B. \& Choi, S., The methods of identification, analysis, and removal of endocrine disrupting compounds (EDCs) in water. Journal of Hazardous Materials 172, pp. 1-12, 2009.

[6] Jacob, M., Guigui, C., Cabassud, C., Darras, H., Lavison, G. \& Moulin, L., Performances of RO and NF processes for wastewater reuse: Tertiary treatment after a conventional activated sludge or a membrane bioreactor. Desalination, 250, pp. 833839, 2010.

[7] Amdany, R., Chimuka, L, Cukrowska, E., Kukučka, P., Kohoutek, J. \& Vrana, B., Investigating the temporal trends in $\mathrm{PAH}, \mathrm{PCB}$ and $\mathrm{OCP}$ concentrations in Hartbeespoort Dam, South Africa, using semipermeable membrane devices (SPMDs). Water SA, 40(3), 2014.

[8] http://www.chemiasoft.com/chemd/TDS. Accessed on: 3 Aug 2015.

[9] Horcas, I., Fernandez, R., Gomez-Rodriguez, J.M., Colchero, J. \& Gomez-Herrero, J., Baro, A.M., WSXM: A software for scanning probe microscopy and a tool for nanotechnology. Rev. Sci. Instrum., 78(1), 2007.

[10] Broeke, J., Pérez, J.M.M. \& Pascau, J., Image Processing with ImageJ. Second Edition. Packt Publishing, 2015.

[11] Lee, C., Sundar, S., Kwon, J. \& Han, H., Structure-property correlations of sulfonated polyimides. II. Effect of substituent groups on membrane properties. Journal of Polymer Science Part A: Polymer Chemistry, 42(14), pp. 3621-3630, 2004.

[12] Emadzadeh, D., Lau, W.J., Rahbari-Sisakht, M., Daneshfar, A., Ghanbari, M., Mayahi, A., Matsuura, T. \& Ismail, A.F., A novel thin film nanocomposite reverse osmosis membrane with superior anti-organic fouling affinity for water desalination. Desalination, 368, 106-113, 2015.

[13] Ghosh, A.K. \& Hoek, E.M.V., Impacts of support membrane structure and chemistry on polyamide-polysulfone interfacial composite membranes. Journal of Membrane Science, 336, pp. 140-148, 2009. 
[14] Yu, S., Liu, M., Lü, Z., Zhou, Y. \& Gao, C., Aromatic-cycloaliphatic polyamide thinfilm composite membrane with improved chlorine resistance prepared from m-phenylenediamine-4-methyl and cyclohexane-1,3,5-tricarbonyl chloride. Journal of Membrane Science, 344, pp. 155-164, 2009.

[15] Sarkar, B.N., Venkateswralu, R. Rao, N., Bhattacharjee, C. \& Kale, V., Treatment of pesticide contaminated surface water for production of potable water by a coagulationadsorption-nanofiltration approach. Desalination, 212, pp. 129-140, 2007.

[16] Adeniyi, A., Brooms,T., Mbaya, R.K.K. \& Onyango, M.S., Patricia Popoola, A.P.I., Olukunle, O., Performance evaluation of membrane technology for removal of micro pollutants in Hartbeespoort dam water in South Africa. LUT Scientific and Expertise Publications, Research Reports 63, ISBN 978-952-335-065-6, and ISBN 978-952335-065-3 for electronic publications, 2017. 